\title{
Glyphosate dose modulates the uptake of inorganic phosphate by freshwater cyanobacteria
}

\author{
Damian Drzyzga $^{1} \cdot$ Jacek Lipok $^{1}$ (D)
}

Received: 5 February 2017 /Revised and accepted: 10 July 2017 /Published online: 21 July 2017

(C) The Author(s) 2017. This article is an open access publication

\begin{abstract}
The usefulness of glyphosate [ $N$-(phosphonomethyl)glycine] as a source of nutritive phosphorus for species of halophilic cyanobacteria has been postulated for years. Our results indicate a stimulating effect of glyphosate on the growth of four out of five examined freshwater species, Anabaena variabilis (CCALA 007), Chroococcus minutus (CCALA 055), Fischerella cf. maior (CCALA 067) and Nostoc cf. muscorum (CCALA 129), in a manner dependent on the applied concentration. The most significant stimulation was observed at a dose of $0.1 \mathrm{mM}$ glyphosate. The decrease in the amount of phosphonate, which correlated with microbial growth, demonstrated that glyphosate may play an important role in cyanobacterial nourishment. Surprisingly, the consumption of organic phosphorus did not start when concentrations of inorganic phosphate $\left(\mathrm{PO}_{4}{ }^{3-}\right)$ had fallen dramatically; instead, the assimilation of both types of phosphorus occurred simultaneously. The greatest decrease in the amount of glyphosate was observed during the first week. The uptake of the standard nutrientphosphate $\left(\mathrm{PO}_{4}{ }^{3-}\right)$, was strongly dependent on the xenobiotic concentration. When a concentration of $0.1 \mathrm{mM}$ glyphosate was used, the consumption of phosphate decreased in favour of glyphosate assimilation. Our study revealed for the very first time that the presence of inorganic phosphate significantly enhances the bioavailability of glyphosate. Statistical analysis confirmed that the nutritive usage of glyphosate and the absorption of phosphate are features associated with the herbicide concentration rather than features related to
\end{abstract}

Jacek Lipok

jacek.lipok@uni.opole.pl

1 Faculty of Chemistry, Opole University, Oleska 48, 45-052 Opole, Poland the species of freshwater cyanobacterium. This finding supports the thesis of an important role of organic phosphorus in the formation of cyanobacterial blooms and creates the opportunity of using these cyanobacteria to bind both organic and inorganic forms of phosphorus in microalgal biomasses.

Keywords Glyphosate · Cyanobacteria · Phosphonate · Phosphorus uptake $\cdot$ Phosphorus binding

\section{Introduction}

Glyphosate [ $N$-(phosphonomethyl) glycine] (NPMG) belongs to group of non-selective herbicides with a broad spectrum of action and is the most commonly used worldwide for weed control (Goldsborough and Brown 1988). Because of its relatively low mammalian toxicity (Rios et al. 2002) and broad range of applications, glyphosate has been the most used pesticide at the global scale for many years, with its price decreasing with each year (Woodburn 2000). The introduction of genetically modified plants resistant to glyphosate (so called "Roundup Ready" (RR), genetically engineered (GE) herbicide-tolerant (HT) plants) has made a great impact on the worldwide consumption of glyphosate in recent years (Coupe et al. 2012). From 1995 to 2014, the worldwide usage of this herbicide (in both agricultural and non-agricultural applications) has risen over 12-fold. The decade from 2004 to 2014 was a period when glyphosate was applied on an unprecedented scale: 6.1 billion $\mathrm{kg}$ of glyphosate was used, which constitutes $71.6 \%$ of the total use worldwide from 1974 to 2014 (Benbrook 2016). Glyphosate residues are often identified in environmental water samples. In 2002, $\mathrm{N}$-phosphonomethyl glycine and AMPA were detected in the Mississippi River Basin at levels above $0.1 \mu \mathrm{g} \mathrm{L}^{-1}$ in $40 \%$ of 
tested streams samples. In 2004 and 2005, glyphosate was detected in 26 and $17 \%$ of samples, respectively, at concentrations above $5 \mu \mathrm{g} \mathrm{L}^{-1}$ (Coupe et al. 2012).

The fate of any pesticide in the environment depends on the physicochemical properties of the compound and the soil and meteorological factors (Salmon-Monviola et al. 2011). The high solubility of glyphosate in water (Battaglin et al. 2005) in combination with surface run-off and washout from the ground increases the chance of introducing this xenobiotic to aqueous systems (Tsui and Chu 2008). It has been suggested that glyphosate is an environmentally friendly chemical compound that does not have a negative impact on other organisms, except plants (Williams et al. 2000). Recently, there have been some reports suggesting its toxic effects on some aquatic organisms (Wang et al. 2016). It has been proven that the presence of glyphosate could change the composition of algae communities at a level of $10 \mu \mathrm{g} \mathrm{L}^{-1}$ (Pesce et al. 2009) and could negatively affect some freshwater phytoplankton strains (Vendrell et al. 2009). NPMG exposure can reduce diatom abundance, as well as enhance the development of cyanobacterial colonies (Vera et al. 2010). The presence of glyphosate could also stimulate the growth of some aquatic photoautotrophs. For example, the cyanobacterium Anabaena variabilis $L$. can not only tolerate treatment with NPMG but is also able to decompose this substance and use it as source of phosphorus (Ravi and Balakumar 1998). This ability of cyanobacteria could contribute the its ecological advantage over other organisms and may lead to the formation of harmful blooms (Smith 2003; O'Neil et al. 2012). The problem of cyanobacterial blooms has become more and more serious from ecological point of view, as well as in terms of the economy and protection of human health (Sharpley and Wang 2014; Khan et al. 2015).

Cyanobacteria are known for their outstanding adaptive capabilities (Kasowska-Żok et al. 2014). These microorganisms play a major role in the global cycling of nitrogen and carbon and are the only group of prokaryotes able to carry out the oxygenic photosynthesis. Species that fix atmospheric nitrogen increase its concentration in the soil. Cyanobacteria possess various environmental adaptations, including the ability to obtain all forms of phosphorus from the environment (Tiwari et al. 2015; Lipok et al. 2007). The secretion of enzymes responsible for the assimilation of phosphorus outside the cell is one of the ways to obtain this nutrient (Ravi and Balakumar 1998). Glyphosate, when is introduced into water reservoirs, increases the pool of existing organic phosphorus (Battaglin et al. 2014). It enters the pool of dissolved organic phosphorus (DOP), which together with a variety of forms of inorganic phosphorus $\left(\mathrm{P}_{\mathrm{i}}\right)$ can be found in oligotrophic waters (Kretz et al. 2015). Although phosphorus, as a nutritive element, is necessary to sustain the growth of primary producers in aquatic environments (Girault et al. 2012), the issue of which form of this nutrient is appropriate for different aquatic species remains unsettled. For years, many attempts have been made to estimate the contribution of phosphonates to total DOP pool. Currently, it is thought that up to $25 \%$ of organic phosphorus in aquatic environments exists in the form of phosphonates; however, it is more likely that this value is approximately 10\% (Van Mooy et al. 2015; Lin et al. 2016). Environmental phosphorus redox cycling determines the DOP pool composition and exerts an indirect impact on phytoplankton communities (Lin et al. 2016; Van Mooy et al. 2015; Benitez-Nelson 2015). Thus, it seems obvious the Pi uptake by microorganisms is limited by the concentration of ambient phosphorus.

Phosphorus metabolism has been well-documented for many species of heterotrophic bacteria. However, the dependency on glyphosate and phosphate consumption is still uncertain for prokaryotic autotrophs such as cyanobacteria. Based on the findings of our study, we hereby report the interactions between five cyanobacterial strains and glyphosate in the context of microbial sensitivity towards glyphosate and the impact of this herbicide on the utilization of inorganic phosphate. Furthermore, the effect of the concentration of this xenobiotic, as the crucial factor for its bioavailability to cyanobacteria, was investigated.

\section{Methods}

\section{Cyanobacterial strains, culturing conditions}

Five species of freshwater cyanobacteria were purchased from the Culture Collection of Autotrophic Organisms (CCALA, Institute of Botany, Academy of Sciences of the Czech Republic, Trebon). They are characterized in Table 1. For a better understanding of the impact and bioavailability of glyphosate, the tested species, representing four out of five taxonomic groups (section) of cyanobacteria (Rippka et al. 1979), were selected with respect to the differences in their colony organization, cell shape, mode of cell division, occurrence in nature, and production of toxins (Castenholz and Waterbury 1989).

Because the selected species are representative of each section, this allows for the study of the specificity of dynamic interactions with NPMG and the cellular response of particular organisms, which can then be broadly applied to cyanobacteria in general.

Prior to being grown in experimental media, cyanobacteria were pre-grown in $50 \mathrm{~mL}$ of BG11 medium (ATCC 616) (Rippka et al. 1979) in 250-mL Erlenmeyer flasks. Microorganisms were revitalized every 21 days by transferring $10 \mathrm{~mL}$ aliquots to $50 \mathrm{~mL}$ of fresh media. Cyanobacteria were cultivated at $24 \pm 1{ }^{\circ} \mathrm{C}$, and the photoperiod was set at $16 \mathrm{~h}: 8 \mathrm{~h}$ (day: night) at $200 \mu \mathrm{mol}$ photons $\mathrm{m}^{-2} \mathrm{~s}^{-1}$ PAR. Pdepleted conditions were obtained by removing $\mathrm{K}_{2} \mathrm{HPO}_{4}$ from 
Table 1 Used cyanobacterial species

\begin{tabular}{lllll}
\hline Strain No & Species & Section & Origin & Habitat \\
\hline CCALA 007 & Anabaena variabilis & IV & USA, Mississippi & Freshwater \\
CCALA 049 & Chroococcidiopsis thermalis & II & Slovakia, Piestany & Thermal mud \\
CCALA 055 & Chroococcus minutus & I & Macedonia, Ohrid & Lake, littoral \\
CCALA 067 & Fischerella cf. maior & V & Switzerland, Aargau, & No available data \\
CCALA 129 & Nostoc cf. muscorum & IV & Mellingen & Poland, Lublin \\
\hline
\end{tabular}

Based on the CCALA, Culture Collection of Autotrophic Organisms, data standard BG11 medium (Bg11-P); in this case it was necessary to balance the potassium concentration by providing this element in the form of $\mathrm{KNO}_{3}\left(34 \mathrm{mg} \mathrm{L}^{-1}\right)$, which resulted in a reduction, the amount of $\mathrm{NaNO}_{3}$ to $1.47 \mathrm{~g} \mathrm{~L}^{-1}$ (to keep the amount of $\mathrm{N}$ balanced). The same conditions were maintained for supporting the growth of experimental cultures. All chemicals necessary to prepare cyanobacterial media were purchased from POCh (Poland).

\section{Glyphosate treatments}

Pure, powdered glyphosate was obtained by applying a procedure used in our laboratory that has been described previously (Lipok et al. 2010). To maintain sterile conditions, appropriate amounts of each tested phosphonate were dissolved in a few millilitres of sterile medium and were added to the final solutions via filtration through sterile membrane syringe filters (Nylon, $0.22 \mu \mathrm{m}$ ).

Tested cyanobacterial strains were cultured for 14 days in BG11 medium supplemented with the following concentrations of glyphosate: $0.05,0.1$ and $0.2 \mathrm{mM}$. The range of applied concentrations was based on previous results (data not shown), and it covers the herbicide doses that do not negatively influence the growth of the majority of examined freshwater cyanobacteria. Concentrations of NPMG above $0.2 \mathrm{mM}$ led to culture dieback over 2 weeks. In all systems, the initial chlorophyll concentration was set at $1 \mathrm{mg} \mathrm{L}{ }^{-1}$. The $\mathrm{PO}_{4}{ }^{3-}$ concentration was the same at the start of all tests - $0.03 \mathrm{~g} \mathrm{~L}^{-1}$ of $\mathrm{K}_{2} \mathrm{HPO}_{4}$. Control cultures were not supplemented with the tested phosphonate. Abiotic controls to assess glyphosate stability and its tendency to adsorb on glassware used in this experiment were also performed. Briefly, sterile $0.1 \mathrm{mM}$ solutions of glyphosate in $\mathrm{Bg} 11$ medium specifically formulated for cyanobacteria were maintained at the same light, temperature and humidity conditions as used for the experimental cultures. The concentration of NPMG at the beginning and at end of the experiment was determined via highperformance liquid chromatography (HPLC). All experiments were carried out in triplicate $(n=3)$.

\section{The evaluation of the growth of cyanobacteria based on the content of chlorophyll}

Determination of cyanobacterial growth based on measurements of total chlorophyll content over time in the experimental cultures was performed according to the method described previously (Lipok et al. 2010). Briefly, at 3-4-day intervals, growth measurements were made in harvested samples as follows: (i) 1-mL samples were taken from each repetition, and (ii) the cells were sedimented via centrifugation for $5 \mathrm{~min}$ at $13000 \times \mathrm{g}$, (iii) obtained pellets were resuspended in $0.9 \mathrm{~mL}$ of methanol, and solubilization was allowed to proceed for $20 \mathrm{~min}$ in the dark, with occasional mixing, and then (iv), step ii was repeated. Total chlorophyll content in the supernatant was determined spectrophotometrically based on Arnon's formula: Total chlorophyll $[a+b]=20.21 \mathrm{~A}_{645}+8.02 \mathrm{~A}_{663}$ (Porra 2002).

\section{Quantitative determination of phosphate and phosphonate levels in cyanobacterial cultures}

Media harvested during the experiments were separated from the cells via centrifugation at $13,000 \times g$ for $5 \mathrm{~min}$. Then, the cell-free supernatants were frozen and were kept at $-28{ }^{\circ} \mathrm{C}$ until the day of analysis.

${ }^{31} \mathrm{P}$ NMR (nuclear magnetic resonance) spectroscopy was carried out to estimate the amount of inorganic phosphate. Samples $(450 \mu \mathrm{L})$ of media were placed in NMR cuvettes $(5 \mathrm{~mm}$ in diameter) and mixed with $123 \mu \mathrm{L}$ of a $0.01 \mathrm{M}$ solution of EDTA. ${ }^{31} \mathrm{P}$ NMR experiments were performed using a Bruker Avance DRX 400 spectrometer operating at $161.976 \mathrm{MHz}$. Data were acquired at $20 \pm 1{ }^{\circ} \mathrm{C}$ using a $30^{\circ}$ pulse, a $1.337 \mathrm{~s}$ acquisition time and a 0.5 -s relaxation delay, with a $20 \mathrm{~Hz}$ spin rate $(5-\mathrm{mm}$ probe). The number of scans was 900, with an FID resolution of $0.374 \mathrm{~Hz}$. The 0.01 $\mathrm{M}$ solution of $\mathrm{H}_{3} \mathrm{PO}_{4}$ was used as the internal reference standard. The concentration of phosphate in these samples was estimated by integrating the area of its 
signal with respect to that of the internal reference standard using MestReNova version 6.0.2 software.

The amount of NPMG was estimated based on the results of the HPLC measurements. Pre-column derivatization with $p$-toluenesulphonyl chloride was carried out to quantify residual glyphosate levels in post-culture media according to a procedure described previously (Khrolenko and Wieczorek 2005). After the derivatization process, according to a previously described method (Lipok et al. 2010), the samples were injected onto a $4.6 \mathrm{~mm} \times 250 \mathrm{~mm}$ Phenomenex Kinetex Evo $\mathrm{C}-18$ column. The mobile phase was composed of $0.01 \mathrm{M} \mathrm{KH}_{2} \mathrm{PO}_{4}(\mathrm{pH} 2.3)$ and $\mathrm{MeCN}(90: 10, v / \mathrm{v})$. The flow rate for isocratic separation was adjusted to $1 \mathrm{~mL} \mathrm{~min}^{-1}$, with the eluate monitored at $240 \mathrm{~nm}$. Each sample was measured in triplicate. Concentrations of glyphosate were computed based on calibration curves established using a stock solution of NPMG in Bg11 medium.

Agglomerative hierarchical clustering (AHC) was performed using XLSTAT version 2014.5.03. Dissimilarity was described by the Gower coefficient, and the unweighted pairgroup average agglomerative method was used.

\section{Estimation of generation (doubling) times}

Generation (doubling) times (DTs) of the tested cyanobacteria were calculated mathematically. The growth curve was fitted by applying the exponential growth eq. $Y=Y_{0} \mathrm{e}^{\left(\mathrm{k}^{*} x\right)}$, where $k$ is the growth rate constant, expressed as a reciprocal of the time units, and $x$ is time. Therefore, generation time (DT) was computed as $\ln (2) / k$. For each replication, the DT was calculated separately, and hence, this value is presented as the mean \pm S.D. $(n=3)$. Computations were performed using GraphPad Prism version 5.01.

\section{Results}

\section{Glyphosate effectively stimulates cyanobacterial growth}

The concentration of chlorophyll in cyanobacterial cells was the main factor taken in to account in evaluating the impact of glyphosate on the growth of bacteria. Significant stimulation was noticed for the four tested species treated with 0.1 and $0.2 \mathrm{mM}$ doses of NPMG (Fig. 1), with CCALA 007 (hereafter, Anabaena 007) and CCALA 129 (Nostoc 129) cultures containing almost twofold higher concentrations of chlorophyll than their respective controls. Interestingly, the growth of both strains was supported similarly by the lowest tested glyphosate dose $-0.05 \mathrm{mM}$.

A dose of $0.1 \mathrm{mM}$ glyphosate was the only concentration that stimulated (almost twofold increase) the growth of Fischerella maior (CCALA 067), and similar to the effect of the $0.2 \mathrm{mM}$ dose, it induced an approximately $30 \%$ increase

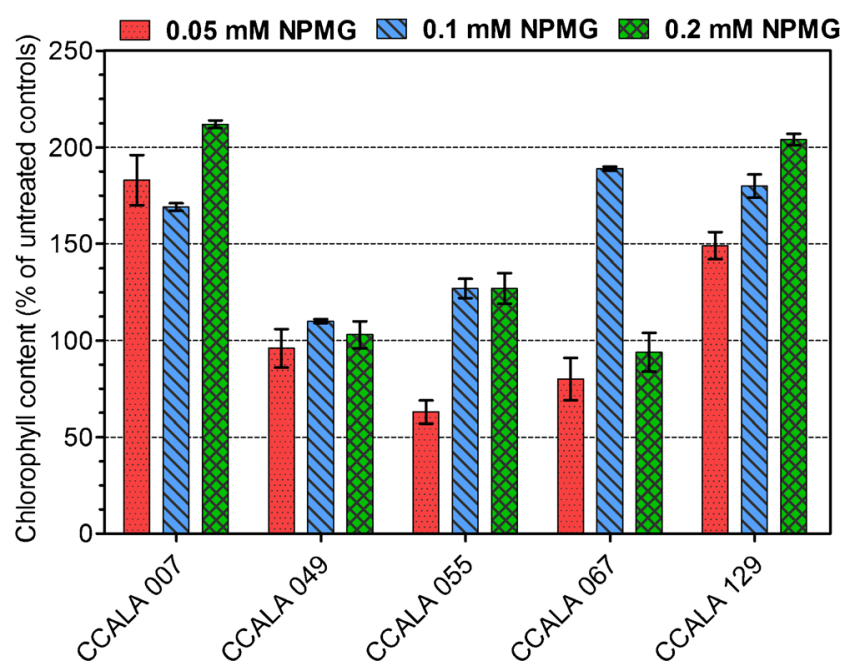

Fig. 1 Effect of glyphosate treatment on cyanobacterial growth after 2 weeks. Results are given as a percentage growth relative to untreated controls $(\%)$ with \pm S.D. for three replicates

in the content of chlorophyll in Chroococcus minutus (CCALA 055) cultures. Glyphosate neither hampered nor supported the growth of Chroococcidiopsis thermalis (CCALA 049). The stimulation of microbial growth could be explained as an effect resulting from one or both of the following phenomena: (i) the intensification of inorganic phosphate uptake and (ii) the acquisition of nutritive phosphorus from glyphosate.

\section{Utilization of inorganic phosphate in relation to glyphosate concentration}

The co-existence of two studied forms of phosphorus (Pi and NPMG) in the environment suggested the importance of simultaneously assessing the consumption of inorganic phosphate, represented as the amount of residual phosphate present during the growth of cyanobacteria and the utilization of glyphosate, which was expressed based on the extent of its decrease over the course of the experiments.

The results for cyanobacterial colonies not treated with glyphosate (controls) (Fig. 2.) revealed a high-level of phosphate decline during the first week. The exceptions were Anabaena 007 and Chroococcus 055, for which the decrease of $P_{i}$ was slower and continued into the eleventh day. The disappearance of phosphorus, an essential nutrient for intensive cellular metabolism (Garcia et al. 2016), coincided in time (first week of treatment) with a doubling of the growth of cells (Table 2. and Fig. 3.). The dynamics of the growth of Anabaena 007 cultures, with a representative plot shown in Fig. 3, clearly demonstrates the stimulating effect of the applied glyphosate.

According to our findings, glyphosate influenced phosphate uptake by cyanobacterial cells in a dose-dependent manner (Fig. 4.). Tracking concentrations of phosphate, a 


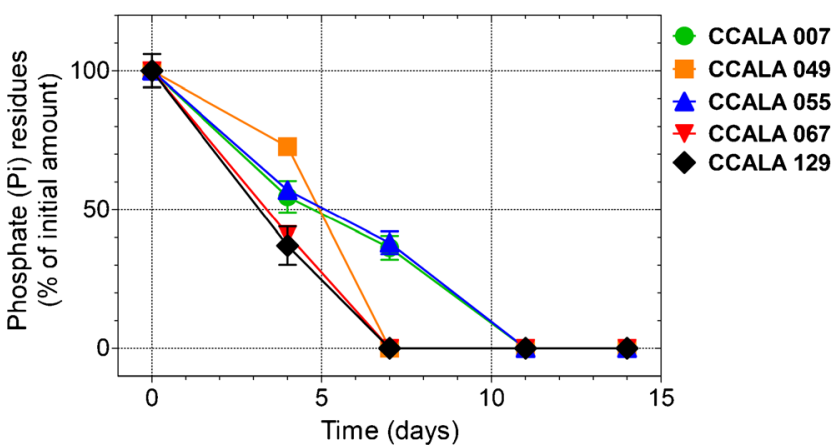

Fig. 2 Percentage decrease of phosphate content in cultures of cyanobacteria not treated with glyphosate (controls). Measurements were performed using NMR spectroscopy; thus, the baseline value should be regarded as the concentration below the limit of detection ( $80 \mu \mathrm{M}$ in this study) and does not necessarily imply a total lack of phosphate. For each species, the values were calculated separately \pm S.D. for three replicates

reduction in the absorption of inorganic forms of phosphorus was observed, which appeared mostly at a concentration of $0.1 \mathrm{mM}$ glyphosate. This dose of NPMG resulted in colonies of Anabaena 007, Chroococcidiopsis 049 and Fischerella 067 limiting or even ceasing the use of phosphate, which was detected up to the very end of experiment. This finding strongly demonstrates the relationship between phosphonate and phosphate in phosphorus use by cyanobacteria. Only in the case of Chroococcus 055 did the uptake of phosphate appeared to be uninfluenced by glyphosate. Between the fourth and seventh day of subculturing with $0.1 \mathrm{mM}$ NPMG for Chroococcidiopsis 049 and Fischerella 067 and with $0.05 \mathrm{mM}$ glyphosate for Nostoc 129, a significant increase in the total amount of available inorganic phosphate in the medium was noticed (Fig. 4.). This finding, along with the simultaneous rapid growth of cyanobacteria, indicates the assimilation of glyphosate.

Table 2 Generation times (DTs) of examined cyanobacteria in relation to the concentration of glyphosate added to the medium

\begin{tabular}{|c|c|c|c|c|}
\hline \multirow[t]{3}{*}{ Strain } & \multicolumn{4}{|c|}{ Concentration of NPMG (mM) } \\
\hline & 0.0 & 0.05 & 0.1 & 0.2 \\
\hline & \multicolumn{4}{|c|}{ Generation (doubling) time (days) } \\
\hline Anabaena 007 & $3.8 \pm 0.3$ & $2.7 \pm 0.3$ & $2.8 \pm 0.1$ & $2.6 \pm 0.1$ \\
\hline Chroococcidiopsis 049 & $4.1 \pm 0.7$ & $3.5 \pm 0.5$ & $3.4 \pm 0.4$ & $4.4 \pm 0.4$ \\
\hline Chroococcus 055 & $4.5 \pm 0.3$ & $3.3 \pm 0.3$ & $3.0 \pm 0.1$ & $2.9 \pm 0.4$ \\
\hline Fischerella 067 & $5.5 \pm 1.0$ & $6.1 \pm 2.5$ & $4.1 \pm 0.3$ & $5.1 \pm 0.1$ \\
\hline Nostoc 129 & $11.0 \pm 0.1$ & $8.4 \pm 0.7$ & $5.7 \pm 0.1$ & $5.3 \pm 0.4$ \\
\hline
\end{tabular}

Generation times, given in days, were calculated for the first week of cyanobacterial growth in the presence of various concentration of glyphosate $(\mathrm{mM})$. The results are presented as the means \pm S.D. for three replicates. When NPMG stimulated cyanobacterial growth, the DT was shorter than for the appropriate control

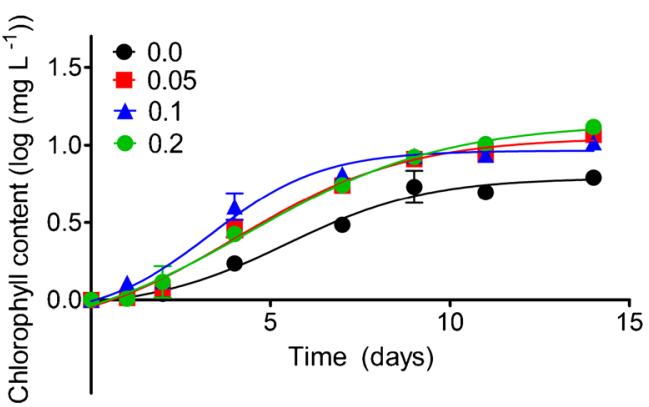

Fig. 3 Time course of Anabaena 007 growth in the presence of various concentration of NPMG; phosphonate was added to the standard BG11 medium. Growth was measured as the increase of chlorophyll content, and data were related to time (days). Each point is the mean \pm S.D. for three replicates

\section{Assimilation of glyphosate is a dose-dependent process}

Since no statistically significant changes were observed in the concentration glyphosate alone, which maintained a stable $(100 \pm 5 \%)$ level in the BG11 medium (substrate control) during 2 weeks of incubation, the decrease in its amount in the experimental treatments resulted from microbial consumption. The dose-dependent assimilation of glyphosate by microorganisms (expressed as its diminishing concentration in culture media) was investigated thorough HPLC analysis of post-culture media (Fig. 4.). For the majority of the tested strains, a significant loss of glyphosate was detected between the fourth/seventh and the eleventh day of the experiment, which coincided with the period of logarithmic cyanobacterial growth and the dominance of the second generation of cells (Table 2.).

NPMG reductions were found to be dependent on its concentration in the medium and on the studied strain. When the tested compound was present at $0.2 \mathrm{mM}$, a greater reduction was observed. In Fischerella 067 cultures, a loss of over $42 \%$ (equivalent to an $\sim 90 \mu \mathrm{M}$ change) of glyphosate was observed, whereas for Chroococcus 055 and Nostoc 129, the decrease in glyphosate was slightly above $25 \%$ of its initial amount. The same concentration of NPMG $(0.2 \mathrm{mM})$ seemed to be unavailable to Anabaena 007 and Chroococcidiopsis 049 .

The fact that DTs for most species were less than 5 days (Table 2) indicates that is was primarily the second generation of cyanobacterial cells that were responsible for the use of glyphosate. This process was especially effective in media initially containing $100 \mu \mathrm{M}$ NPMG, where within 14 days, all five species of tested cyanobacteria had reduced the concentration by over $30 \mu \mathrm{M}$, with Nostoc 129 reducing it by $50 \mu \mathrm{M}$.

AHC allowed the identification of the cyanobacterial response to the presence of NPMG for certain classes of organisms (Fig. 5), which opened the way to understanding glyphosate's influence on the microbial strategy towards 
Fig. 4 Impact of glyphosate on inorganic phosphorus

(phosphates) uptake (left column), and the changes in its

concentration resulting from the response of cyanobacterial cells (right column). The amount of residual phosphate in the experimental media (left column) was measured using ${ }^{31} \mathrm{P}$ NMR spectroscopy, with $0.01 \mathrm{M}$ phosphoric (V) acid used as an internal standard. The calculated values were compared with those from day 0 and expressed as a percent $(\%) \pm$ S.D. for three replicates. The amount of NPMG on the following days of the experiment (right column) was determined based on HPLC analysis of post-culture media. The disappearance of glyphosate is expressed in $\mu \mathrm{mol} \mathrm{L} \mathrm{L}^{-1} \pm$ S.D. for three replicates
CCALA 007

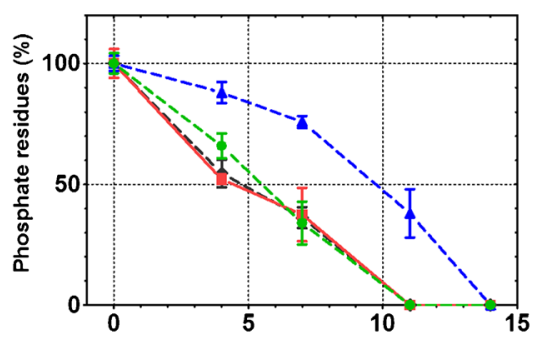

CCALA 049

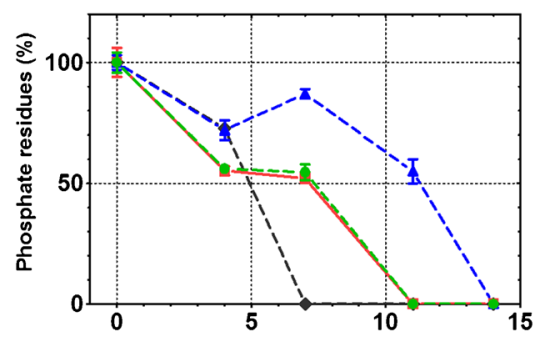

CCALA 055

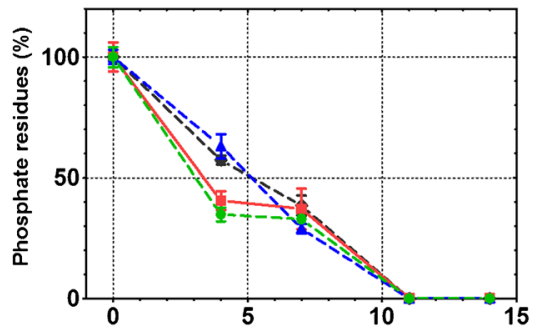

CCALA 067

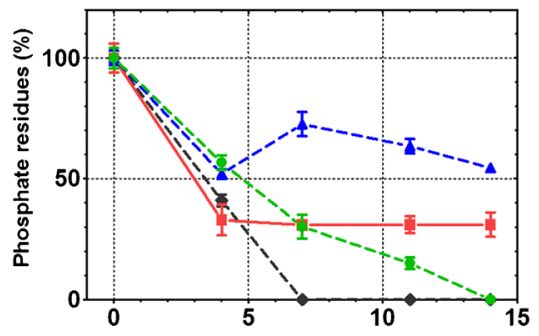

CCALA 129

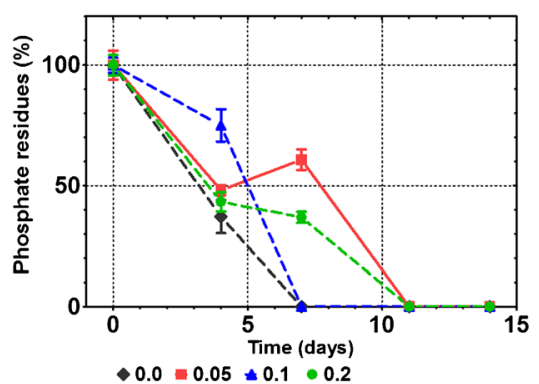

CCALA 007

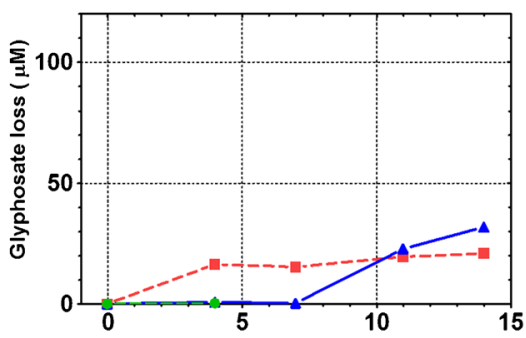

CCALA 049

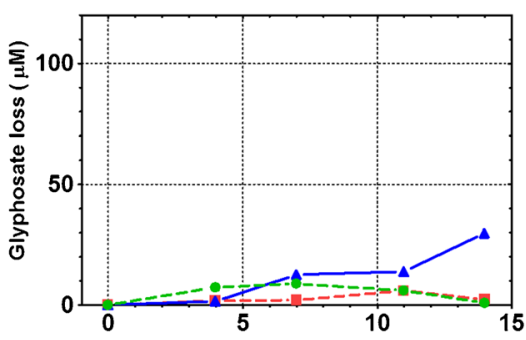

CCALA 055

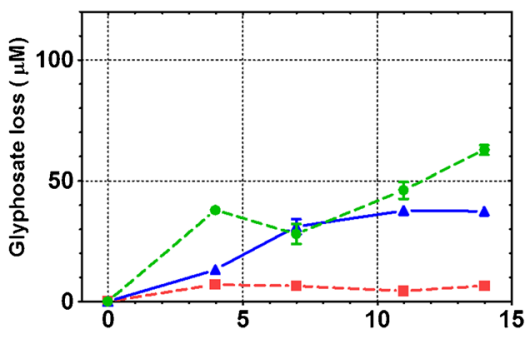

CCALA 067

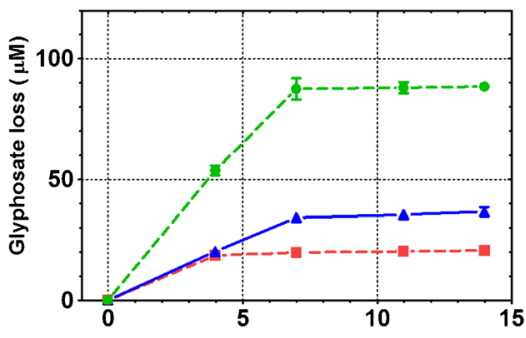

CCALA 129

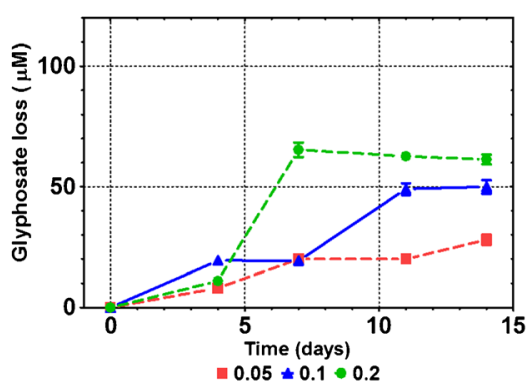

phosphorus consumption. The primary aim of clustering was to determine which of the tested microorganisms use similar strategies when these two different forms of phosphorus are offered. The presence of two separate clusters, one grouping the experimental results in relation to the consumption of inorganic phosphorus and the second containing mainly the results reflecting the reduction in glyphosate, indicate that with respect to the amount of each form of nutritive phosphorus 


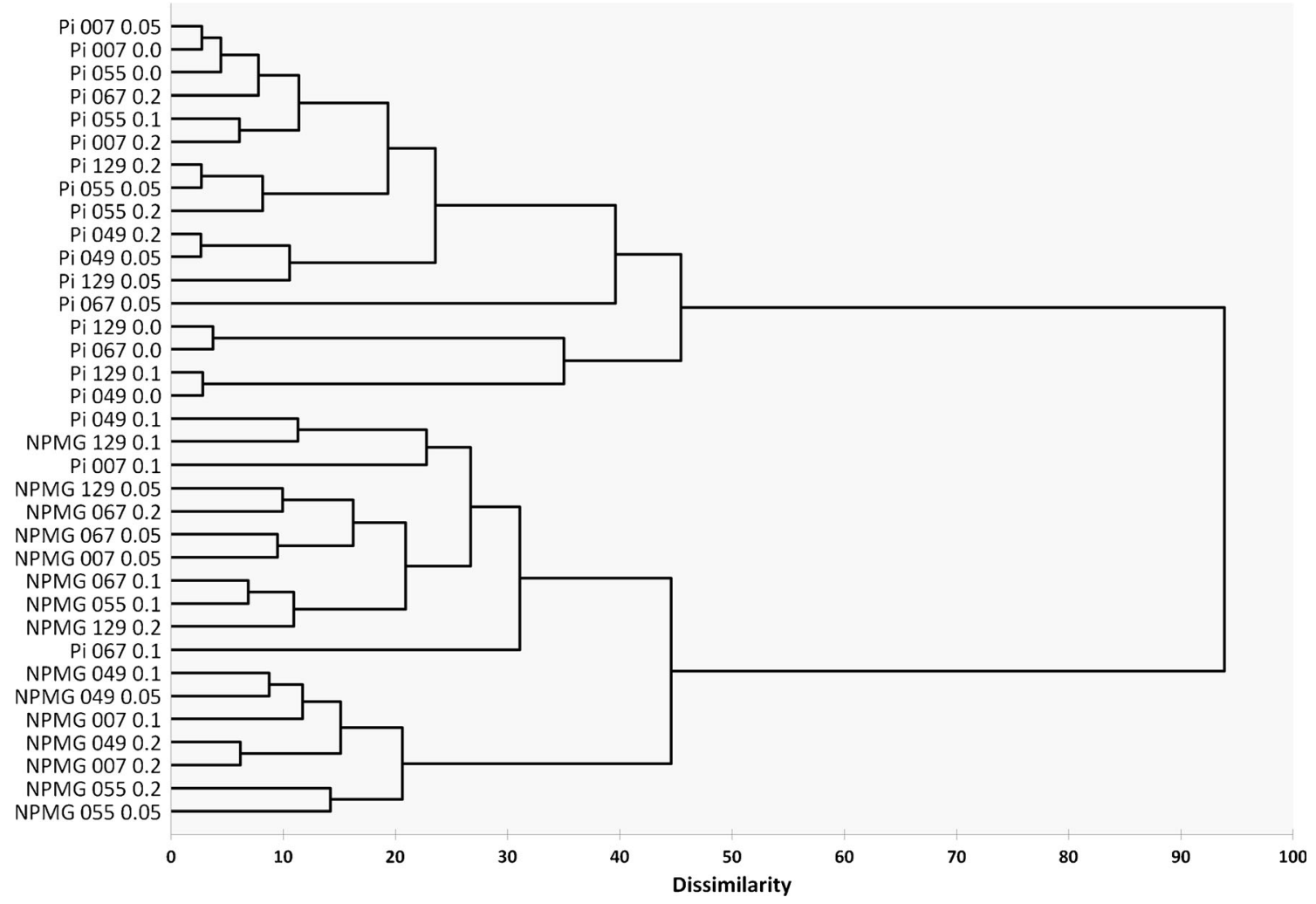

Fig. 5 Agglomerative hierarchical clustering (AHC) for residual amounts of inorganic phosphate and glyphosate in cyanobacterial cultures in the presence of various phosphonate concentrations until the 11th day (Gower coefficients with the agglomeration method: unweighted pair-group average). Pi residual inorganic phosphate, NPMG residual phosphonate available in the medium, the examined strains used different strategies. Moreover, a deeper analysis of the clustering results, combined with the quantification of phosphorus consumption, proved that glyphosate affects $\mathrm{PO}_{4}{ }^{3-}$ uptake and that this impact depended on the concentration of glyphosate added. For Anabaena 007, $0.05 \mathrm{mM}$ NPMG did not affect phosphate assimilation when compared to the control. Nonetheless, in colonies of Fischerella 067 and Nostoc 129, the addition of $0.05 \mathrm{mM}$ glyphosate dramatically changed the manner of $P_{i}$ consumption with respect to untreated cells. The fact that glyphosate at a concentration of $0.1 \mathrm{mM}$ interacts with phosphate uptake in a manner dependent on the strategy of the a certain strain was clearly shown for three species: Fischerella 067, Chroococcidiopsis 049 and Anabaena 007, which showed the highest dissimilarity compared to the rest of the strains.

In the light of these results, the disappearance of phosphate from the growth medium was not solely dependent on the concentration of glyphosate. Interestingly, the decrease in glyphosate seemed to also strongly depend on the appropriate concentration of NPMG. Different concentrations, such as $0.05 \mathrm{mM}$ for Fischerella 067 and Anabaena 007, $0.1 \mathrm{mM}$ for Fischerella 067 and Chroococcus 055, and the highest concentration of $0.2 \mathrm{mM}$ for Anabaena 007 and Chroococcidiopsis 049, resulted in groups showing similar responses.

\section{Glyphosate utilization is enhanced by inorganic phosphate}

When glyphosate (in the dose $0.1 \mathrm{mM}$ ) was the sole phosphorus source in media, the tested cyanobacteria did not exhibit satisfactory growth during the 2 weeks of the experiment (data not published), and during this time, the concentrations of this substance decreased only moderately. The HPLC analysis of cyanobacterial postculture media revealed that in addition to glyphosate affecting phosphate assimilation in a dose-dependent manner, the presence of inorganic phosphate also influences NPMG availability (Fig. 6.). The results obtained from both BG11 and BG11-P media show that the reduction in glyphosate concentration after 2 weeks in Pidepleted conditions was less by approximately $20 \mu \mathrm{M}$. It can be concluded from this that a mutually dependent impact of both form of phosphorus was observed in all experiments. 


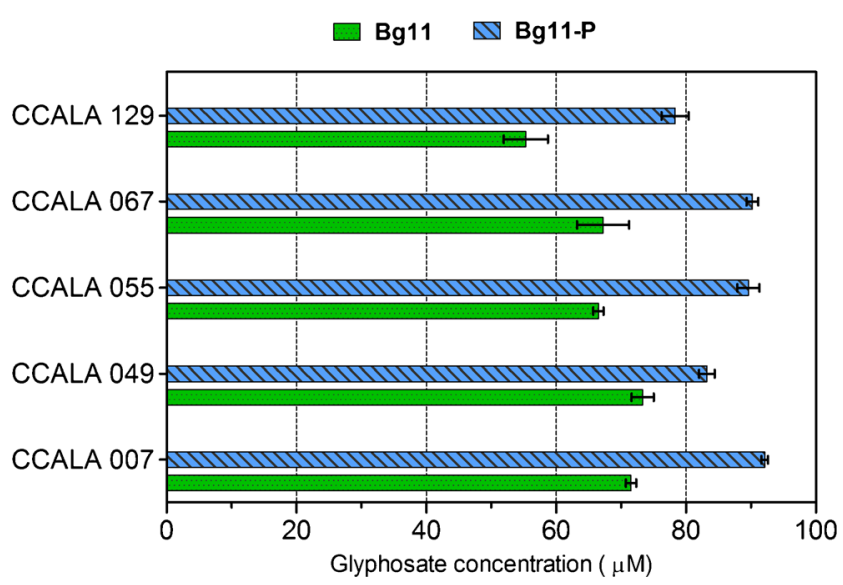

Fig. 6 Glyphosate concentration in cyanobacterial cultures after 2 weeks. In all cases, the initial amount of NPMG was $100 \mu \mathrm{M}$; however, in BG11 media, this substance was an additional source of phosphorus along with $\mathrm{Pi}$, while in BG11-P, it was the sole available source of this element. The results are given \pm S.D. for three replicates

\section{Discussion}

This study showed that the uptake of inorganic phosphate $\left(\mathrm{PO}_{4}{ }^{3-}\right)$ by freshwater cyanobacteria, which had grown in the presence of glyphosate, was correlated with the provided dose of this herbicide. Thus, the supplementation of media with glyphosate affected the uptake of $\mathrm{PO}_{4}{ }^{3-}$ by the cells. Some of following cellular response strategies have been predicted: (1) increase or (2) decrease in the rate of $\mathrm{P}_{\mathrm{i}}$ consumption, (3) maintaining consumption at the same level, or (4) discontinuation of the use of inorganic phosphorus. However, the last response seemed to be almost improbable in the context of the proven bioavailability of phosphates and the importance of phosphorus for the development of bacterial colonies (Schweitzer and Simon 1995; Toolan et al. 1991).

For colonies not treated with NPMG, inorganic phosphorus loss was highest in the first seven (or 11) days of culturing, which coincides with the logarithmic phase of cyanobacterial growth. Obviously, such a high demand is related to many aspects of the regulation of cellular processes, including the phosphorylation of proteins and biosynthesis of intracellular components, because phosphorus-containing compounds are involved in many metabolic pathways (Dick et al. 2011; Wu et al. 2003; Heath et al. 2016). It is also known that phosphorus limitations can directly affect the composition of bacterial cell walls (Liu et al. 2016). Therefore, the demand for phosphorus is correlated with an attempt to maintain phosphorus homeostasis in cyanobacterial cells.

Results of experiments with glyphosate have shown that its presence affects the rate of microbial consumption of inorganic phosphorus. Decreasing concentrations of NPMG together with a growth rate of experimental colonies that exceed that of their respective controls undoubtedly demonstrates the importance of this phosphonate as a nutrient fully equivalent to $\mathrm{PO}_{4}{ }^{3-}$. The exception was Chroococcus 055 ; in this case, $\mathrm{Pi}$ management was not affected by glyphosate. Conceivably, the reason for this was the cellular organization of the colony because this species is the only one among of all of the examined strains that forms colonies composed of two, four, or more cells sheltered by a transparent sheath constructed mainly of polysaccharides. Such a natural barrier usually limits the migration of elements/nutrients to inside the colony (Song et al. 2015).

Glyphosate, when tested in the applied doses, did not show any lethal impact on freshwater cyanobacteria. Furthermore, the growth-supporting effect was enhanced with increasing doses of NPMG. This was expected because it has already been proven for the halophilic cyanobacterium Spirulina platensis (Lipok et al. 2007). Hence, phosphorus-containing xenobiotics may serve as a useful source of nutritive phosphorus, and the intensity of their uptake depends more on their concentration than on the taxonomic classification of the species. Our results show that glyphosate is utilized by cyanobacteria mainly in the logarithmic phase of their growth, when its use prevails over that of phosphate, which is used more in the lag phase. Therefore, the presence of glyphosate at appropriate concentrations is a highly significant factor for the phosphorus utilization strategy of cyanobacteria. It has been postulated that phosphorus uptake from the DOP pool may dominate over Pi uptake but only when the available DOP is in excess (Cotner and Wetzel 1992). In our study, this relation was maintained only for the highest applied concentration of NPMG, $0.2 \mathrm{mM}$, which was equivalent to $6.20 \mathrm{mg} \mathrm{L}^{-1}$ of P. Moreover, in this case, the amounts of DOP and dissolved inorganic phosphorus-DIP (DIP was always present at an initial concentration of $5.34 \mathrm{mg} \mathrm{L}^{-1} \mathrm{P}$ ) were very close to each other. Therefore, the utilization of NPMG, especially when it was tested at lower concentrations, occurred in a more specific manner. The possibility that the consumption of glyphosate, which was the only form of DOP present, was associated with the secretion of enzymes responsible for the acquisition of phosphorus from organic molecules should not be excluded (Singh et al. 2006). It has been proven that 5 days of culturing in the presence of glyphosate evokes an increase in the concentration of extracellular proteins and carbohydrates, as was demonstrated for several species of green algae: Scenedesmus quadricauda, Chlorella kessleri and Raphidocelis subcapitata (known as Selenastrum capricornutum) (Maršálek 1996).

It was predicted that unfavourable growth conditions resulting from phosphate $(\mathrm{Pi})$ depletion in media would intensify NPMG uptake due to the necessity of supplying this essential nutrient. Instead, our study, for the very first 
time, revealed that it was the presence of inorganic phosphate that significantly enhanced the bioavailability of glyphosate. It is thought that in millimolar concentrations, glyphosate diffuses through membranes. In contrast, at micromolar levels, the transportation of this substance is accomplished by high affinity phosphate transporters that show a low affinity towards the phosphonate (Hetherington et al. 1998). Such transportation would result in only small amounts of NPMG being absorbed by cells. The regulation of Pi transport in microorganisms is often under Pho (phosphate) regulon control, which could sense the environmental concentration of $\mathrm{Pi}$ and, if phosphate appears to be limited, influence the expression of relevant genes. This up- and down-regulatory system in bacteria is composed of the protein pair PhoB-PhoR (Tommassen et al. 1982), which in the case of cyanobacteria is under the control of the histidine kinase-response regulator pair SphS-SphR (Juntarajumnong et al. 2007). Extracellular levels of Pi are detected by the PstSCAB complex (Phosphate Specific Transporter), which in conditions of surplus phosphate keeps the whole system inactive. When extracellular concentrations of Pi are below $4 \mu \mathrm{M}$, a conformational changes in the PstSCAB complex occurs, leading to the phosphorylation of the transcription regulator PhoB, which after dissociation from PhoR binds to the appropriate DNA region (Makino et al. 1988; Lamarche et al. 2008). This sequence of events results in gene expression and the activation of many hydrolytic enzymes (phosphatases) involved in DOP utilization (SantosBeneit 2015). It is hard to predict whether all of these phenomena took place in our experiments; nevertheless, the reduction in glyphosate content in experimental media seems to confirm the occurrence of these processes.

It has been proved that cyanobacteria play a major role in nitrogen, carbon and phosphorus cycling in nature (Forlani et al. 2015). However, the strains that utilize aminophosphonates seem using these compounds as nutrients, rather as a source of phosphorus, than nitrogen. Such a thesis is supported from studies on the availability of both: phosphorus and nitrogen for S. platensis, which demonstrated that inorganic nitrogen contained in medium in the form of sodium nitrate, was definitely more preferable, than nitrogen in the form of aminophosphonate (Forlani et al. 2011). In regard to our experiments, applied media: BG11 and BG11-P contained standard nitrogen source-sodium nitrate at the concentration of $1.5 \mathrm{~g} \mathrm{~L}^{-1}$, and such a surplus of nitrogen, in highly preferable form of $\mathrm{NaNO}_{3}$, makes glyphosate unlikely to be a N-source per se. Moreover, in our study, we examined diazotrophic species with capacity to assimilate atmospheric $\mathrm{N}_{2}$. Thus, in our opinion, cyanobacterial strategy to use phosphonate as nitrogen source instead of $\mathrm{NaNO}_{3}$, appears unlikely.
Much earlier, in 1993 Martensson tried to assess whether the nitrogen assimilation expressed as nitrogen fixing activity in cyanobacteria could be inhibited by glyphosate addition, and she did not found any remarkable differences between controls and organisms treated by glyphosate (Martensson 1993). From the other hand, in 2016, Bodkhe and Tarar found that for six cyanobacterial strains, low doses of glyphosate even stimulated fixation of $\mathrm{N}_{2}$ (Bodkhe and Tarar 2016). Therefore, it cannot be excluded that the management of nitrogen in the cells of cyanobacteria might be affected by glyphosate, but the specific action is still unclear and it is worth further elucidation.

Glyphosate can be decomposed by many bacterial strains (Cook et al. 1978; Lipok et al. 2007; Bujacz et al. 1995; Gomez-Garcia et al. 2011; Dyhrman et al. 2006; Singh 2009; Ford et al. 2010; Sviridov et al. 2015; Zhao et al. 2015). It has been proven that the presence of heterotrophic bacteria in cultures is sometimes connected to the ability of cyanobacteria to degrade organic compounds, indicating that not just cyanobacteria themselves are responsible for such activity (Abed and Köster 2005). However, the utilization of glyphosate presented in our study, as well as its impact on Pi uptake, seems unlikely to be related to the actions of heterotrophic bacteria on a significant scale. Continuous control of the axenic purity of the experimental cultures through microscopic observations strongly suggests that the contribution of cyanobacteria to DOP and DIP mineralization in the environment seems unquestioned. Nevertheless, phosphate metabolism in cyanobacteria is a complex issue because it has been proven that organisms belonging to the same genus can decompose the same substance in completely different ways (Gomez-Garcia et al. 2011). Available sequenced genomes of cyanobacteria are still not complete; therefore, the hydrolytic action of many enzymes related to the Pho regulon (e.g., C-P lyase) is based on hypothetical suppositions.

It is worth emphasizing that the results of our study indicate that the most popular herbicide worldwide may benefit cyanobacteria by providing a source of nutritive phosphorus that is as beneficial as inorganic phosphate. This finding, when correlated with the data on the presence of NPMG in surface waters, supports the thesis of an important role of organic phosphorus in cyanobacterial blooms. Moreover, it creates the opportunity of using cyanobacteria to bind excessive amounts of both organic and inorganic forms of phosphorus in microalgal biomasses.

Acknowledgements The authors thank Dr. Dorota Wieczorek for her assistance during the NMR experiments and Prof. Paweł Kafarski for his inspiration in discussing the ecological role of phosphonate compounds. This study was supported by the National Science and Development Centre of Poland under grant No. PBS3/B8/25/2015. 


\section{Compliance with ethical standards}

Conflict of interest The authors declare that they have no conflict of interest.

Open Access This article is distributed under the terms of the Creative Commons Attribution 4.0 International License (http:// creativecommons.org/licenses/by/4.0/), which permits unrestricted use, distribution, and reproduction in any medium, provided you give appropriate credit to the original author(s) and the source, provide a link to the Creative Commons license, and indicate if changes were made.

\section{References}

Abed RMM, Köster J (2005) The direct role of aerobic heterotrophic bacteria associated with cyanobacteria in the degradation of oil compounds. Int Biodeter Biodegr 55:29-37

Battaglin WA, Kolpin DW, Scribner EA, Kuivila KM, Sandstrom MW (2005) Glyphosate, other herbicides, and transformation products in Midwestern streams, 2002. J Am Water Resour Assoc 41:323-332

Battaglin WA, Meyer MT, Kuivila KM, Dietze JE (2014) Glyphosate and its degradation product AMPA occur frequently and widely in U.S. soils, surface water, groundwater, and precipitation. J Am Water Resour Assoc 50:275-290

Benbrook CM (2016) Trends in glyphosate herbicide use in the United States and globally. Environ Sci Eur 28(1). doi:10.1186/s12302016-0070-0

Benitez-Nelson C (2015) Ocean chemistry. The missing link in oceanic phosphorus cycling? Science 348:759-760

Bodkhe SS, Tarar JL (2016) Impact of herbicide glyphosate on metabolic activities of cyanobacterial species. Phykos 46:1-6

Bujacz B, Wieczorek P, Krzysko-Lupicka T, Golab Z, Lejczak B, Kafarski P (1995) Organophosphonate utilization by the wild-type strain of Penicillium notatum. Appl Environ Microbiol 61:29052910

Castenholz RW, Waterbury JB (1989) Taxa of the cyanobacteria. In: Bergey's manual of systematic bacteriology vol 3. Williams and Wilkins, Baltimore, MD

Cook AM, Daughton CG, Alexander M (1978) Phosphonate utilization by bacteria. J Bacteriol 133:85-90

Cotner JB, Wetzel RG (1992) Uptake of dissolved inorganic and organic phosphorus compounds by phytoplankton and bacterioplankton. Limnol Oceanogr 37:232-243

Coupe RH, Kalkhoff SJ, Capel PD, Gregoire C (2012) Fate and transport of glyphosate and aminomethylphosphonic acid in surface waters of agricultural basins. Pest Manag Sci 68:16-30

Dick CF, Dos-Santos AL, Meyer-Fernandes JR (2011) Inorganic phosphate as an important regulator of phosphatases. Enzyme Res 2011: 103980. doi: $10.4061 / 2011 / 103980$

Dyhrman ST, Chappell PD, Haley ST, Moffett JW, Orchard ED, Waterbury JB, Webb EA (2006) Phosphonate utilization by the globally important marine diazotroph Trichodesmium. Nature 439: 68-71

Ford JL, Kaakoush NO, Mendz GL (2010) Phosphonate metabolism in Helicobacter pylori. Antonie Van Leeuwenhoek 97:51-60

Forlani G, Bertazzini M, Barillaro D, Rippka R (2015) Divergent properties and phylogeny of cyanobacterial 5-enol-pyruvyl-shikimate-3phosphate synthases: evidence for horizontal gene transfer in the Nostocales. New Phytol 205:160-171

Forlani G, Prearo V, Wieczorek D, Kafarski P, Lipok J (2011) Phosphonate degradation by Spirulina strains: cyanobacterial biofilters for the removal of anticorrosive polyphosphonates from wastewater. Enzym Microb Technol 48:299-305

Garcia NS, Bonachela JA, Martiny AC (2016) Interactions between growth-dependent changes in cell size, nutrient supply and cellular elemental stoichiometry of marine Synechococcus. ISME J 10: 2715-2724

Girault M, Arakawa H, Hashihama F (2012) Phosphorus stress of microphytoplankton community in the western subtropical North Pacific. J Plankton Res 35:146-157

Goldsborough LG, Brown DJ (1988) Effect of glyphosate (roundup formulation) on periphytic algal photosynthesis. Bull Environ Contam Toxicol 41:253-260

Gomez-Garcia MR, Davison M, Blain-Hartnung M, Grossman AR, Bhaya D (2011) Alternative pathways for phosphonate metabolism in thermophilic cyanobacteria from microbial mats. ISME J 5:141149

Heath M, Wood SA, Young RG, Ryan KG (2016) The role of nitrogen and phosphorus in regulating Phormidium sp. (cyanobacteria) growth and anatoxin production. FEMS Microbiol Ecol 92(3). doi: 10.1093/femsec/fiw021

Hetherington PR, Marshall G, Kirkwood RC, Warner JM (1998) Absorption and efflux of glyphosate by cell suspensions. J Exp Bot 49:527-533

Juntarajumnong W, Hirani TA, Simpson JM, Incharoensakdi A, EatonRye JJ (2007) Phosphate sensing in Synechocystis sp. PCC 6803: SphU and the SphS-SphR two-component regulatory system. Arch Microbiol 188:389-402

Kasowska-Żok E, Ostrowska M, Studnik H, Balcerzak L, Żyszka B, Drzyzga D, Bazgier G, Kafarski P, Lipok J (2014) The biotechnological potential of cyanobacteria forming blue-green algal blooms. Chem Aust 68(4):355-362

Khan SJ, Deere D, Leusch FD, Humpage A, Jenkins M, Cunliffe D (2015) Extreme weather events: should drinking water quality management systems adapt to changing risk profiles? Water Res 85: 124-136

Khrolenko MV, Wieczorek PP (2005) Determination of glyphosate and its metabolite aminomethylphosphonic acid in fruit juices using supported-liquid membrane preconcentration method with highperformance liquid chromatography and UV detection after derivatization with p-toluenesulphonyl chloride. J Chromatogr A 1093: $111-117$

Kretz CB, Bell DW, Lomas DA, Lomas MW, Martiny AC (2015) Influence of growth rate on the physiological response of marine Synechococcus to phosphate limitation. Front Microbiol 6:85. doi: 10.3389/fmicb.2015.00085

Lamarche MG, Wanner BL, Crepin S, Harel J (2008) The phosphate regulon and bacterial virulence: a regulatory network connecting phosphate homeostasis and pathogenesis. FEMS Microbiol Rev 32:461-473

Lin S, Litaker RW, Sunda WG (2016) Phosphorus physiological ecology and molecular mechanisms in marine phytoplankton. J Phycol 52: $10-36$

Lipok J, Owsiak T, Młynarz P, Forlani G, Kafarski P (2007) Phosphorus NMR as a tool to study mineralization of organophosphonates - the ability of Spirulina spp. to degrade glyphosate. Enzyme Microb Tech 41:286-291

Lipok J, Studnik H, Gruyaert S (2010) The toxicity of roundup(R) 360 SL formulation and its main constituents: glyphosate and isopropylamine towards non-target water photoautotrophs. Ecotoxicol Environ Saf 73:1681-1688

Liu Y, Alessi DS, Owttrim GW, Kenney JPL, Zhou Q, Lalonde SV, Konhauser KO (2016) Cell surface acid-base properties of the cyanobacterium Synechococcus: influences of nitrogen source, growth phase and N:P ratios. Geochim Cosmochim Acta 187:179-194

Makino K, Shinagawa H, Amemura M, Kimura S, Nakata A, Ishihama A (1988) Regulation of the phosphate regulon of Escherichia coli. 
Activation of pstS transcription by $\mathrm{PhoB}$ protein in vitro. J Mol Biol 203:85-95

Maršálek BRR (1996) Stress factors enhancing production of algal exudates: a potential self-protective mechanism? J Biosci 51(646):650. doi:10.1515/znc-1996-9-1008

Martensson AM (1993) Use of heterotrophic and cyanobacterial nitrogen fixation to study the impact of anthropogenic substances on soil biological processes. Bull Environ Contam Toxicol 50:466-473

O'Neil JM, Davis TW, Burford MA, Gobler CJ (2012) The rise of harmful cyanobacteria blooms: the potential roles of eutrophication and climate change. Harmful Algae 14:313-334

Pesce S, Batisson I, Bardot C, Fajon C, Portelli C, Montuelle B, Bohatier $\mathrm{J}$ (2009) Response of spring and summer riverine microbial communities following glyphosate exposure. Ecotoxicol Environ Saf 72:1905-1912

Porra RJ (2002) The chequered history of the development and use of simultaneous equations for the accurate determination of chlorophylls $a$ and $b$. Photosynth Res 73:149-156

Ravi V, Balakumar H (1998) Biodegradation of the C-P bond in glyphosate by the cyanobacterium Anabaena variabilis L. J Sci Ind Res 57:790-794

Rios C, Salvadó V, Hidalgo M (2002) Facilitated transport and preconcentration of the herbicide glyphosate and its metabolite AMPA through a solid supported liquid-membrane. J Membrane Sci 203:201-208

Rippka R, Deruelles J, Waterbury JB, Herdman M, Stainer RY (1979) Generic assignment, strain histories and properties of pure cultures of cyanobacteria. J Gen Microbiol 111:1-61

Salmon-Monviola J, Gascuel-Odoux C, Garcia F, Tortrat F, Cordier M-O, Masson V, Trépos R (2011) Simulating the effect of technical and environmental constraints on the spatio-temporal distribution of herbicide applications and stream losses. Agric Ecosyst Environ 140: 382-394

Santos-Beneit F (2015) The pho regulon: a huge regulatory network in bacteria. Front Microbiol 6:402. doi:10.3389/fmicb.2015.00402

Schweitzer B, Simon M (1995) Growth limitation of planktonic bacteria in a large mesotrophic lake. Microb Ecol 30:89-104

Sharpley A, Wang X (2014) Managing agricultural phosphorus for water quality: lessons from the USA and China. J Environ Sci (China) 26(9):1770-1782

Singh BK (2009) Organophosphorus-degrading bacteria: ecology and industrial applications. Nat Rev Microbiol 7:156-164

Singh SK, Singh SS, Pandey VD, Mishra AK (2006) Factors modulating alkaline phosphatase activity in the diazotrophic rice-field cyanobacterium, Anabaena oryzae. World J Microb Biot 22:927-935

Smith VH (2003) Eutrophication of freshwater and coastal marine ecosystems. A global problem. Environ Sci Pollut Res 10:126-139
Song W, Zhao C, Mu S, Pan X, Zhang D, Al-Misned FA, Mortuza MG (2015) Effects of irradiation and $\mathrm{pH}$ on fluorescence properties and flocculation of extracellular polymeric substances from the cyanobacterium Chroococcus minutus. Colloids Surf B 128:115-118

Sviridov AV, Shushkova TV, Ermakova IT, Ivanova EV, Epiktetov DO, Leontievsky AA (2015) Microbial degradation of glyphosate herbicides (review). Appl Biochem Microbiol 51:188-195

Tiwari B, Singh S, Kaushik MS, Mishra AK (2015) Regulation of organophosphate metabolism in cyanobacteria. A review. Microbiology 84:291-302

Tommassen J, de Geus P, Lugtenberg B, Hackett J, Reeves P (1982) Regulation of the pho regulon of Escherichia coli K-12. J Mol Biol 157:265-274

Toolan T, Wehr JD, Findlay S (1991) Inorganic phosphorus stimulation of bacterioplankton production in a meso-eutrophic lake. Appl Environ Microbiol 57:2074-2078

Tsui MT, Chu LM (2008) Environmental fate and non-target impact of glyphosate-based herbicide (roundup) in a subtropical wetland. Chemosphere 71:439-446

Van Mooy BA, Krupke A, Dyhrman ST, Fredricks HF, Frischkorn KR, Ossolinski JE, Repeta DJ, Rouco M, Seewald JD, Sylva SP (2015) Phosphorus cycling. Major role of planktonic phosphate reduction in the marine phosphorus redox cycle. Science 348:783-785

Vendrell E, Ferraz DG, Sabater C, Carrasco JM (2009) Effect of glyphosate on growth of four freshwater species of phytoplankton: a microplate bioassay. Bull Environ Contam Toxicol 82:538-542. Vera MS, Lagomarsino L, Sylvester M, Perez GL, Rodriguez P, Mugni H, Sinistro R, Ferraro M, Bonetto C, Zagarese H, Pizarro H (2010) new evidences of roundup (glyphosate formulation) impact on the periphyton community and the water quality of freshwater ecosystems. Ecotoxicology 19:710-721

Wang C, Lin X, Li L, Lin S (2016) Differential growth responses of marine phytoplankton to herbicide glyphosate. PLoS One 11(3): e 0151633

Williams GM, Kroes R, Munro IC (2000) Safety evaluation and risk assessment of the herbicide roundup and its active ingredient, glyphosate, for humans. Regul Toxicol Pharmacol 31:117-165

Woodburn AT (2000) Glyphosate: production, pricing and use worldwide. Pest Manag Sci 56:309-312

Wu P, Ma L, Hou X, Wang M, Wu Y, Liu F, Deng XW (2003) Phosphate starvation triggers distinct alterations of genome expression in Arabidopsis roots and leaves. Plant Physiol 132:1260-1271

Zhao H, Tao K, Zhu J, Liu S, Gao H, Zhou X (2015) Bioremediation potential of glyphosate-degrading Pseudomonas spp. strains isolated from contaminated soil. J Gen Appl Microbiol 61:165-170 